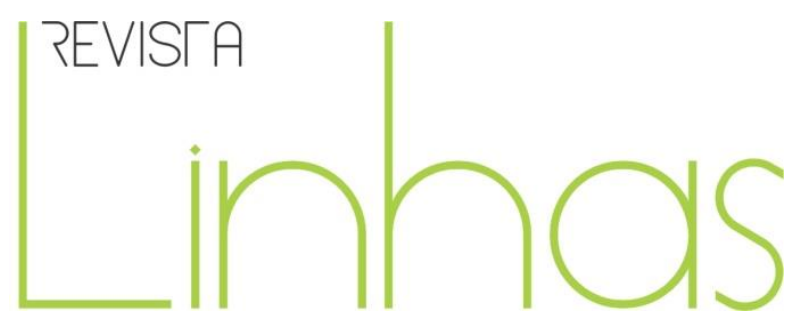

\title{
Ações da Educação Especial no contexto da escola regular: problematizações sobre a inclusão de alunos com deficiência intelectual
}

\begin{abstract}
Resumo
A presente proposição resulta de nossas experiências (na condição de orientadoras) de ações de iniciação à docência efetivadas em escolas regulares por parte dos acadêmicos dos cursos de licenciatura em Educação Especial da Universidade Federal de Santa Maria (UFSM) e objetiva problematizar a atuação do professor de Educação Especial no contexto da escola regular frente ao aluno com deficiência intelectual. Ao considerarmos a conceituação de deficiência intelectual segundo a qual tal deficiência deve ser analisada a partir de cinco dimensões -habilidades intelectuais, comportamento adaptativo (habilidades conceituais, sociais e práticas de vida diária), participação, interações e papéis sociais, saúde (saúde física, saúde mental, etiologia) e contexto (ambientes, cultura) (AAMR, 2006), em interlocução com documentos oficiais que instituem as diretrizes para a Educação Especial na escola inclusiva, parece-nos produtivo analisar de que modo tais dimensões podem ser utilizadas como ferramentas para a efetivação de práticas no Atendimento Educacional Especializado que ultrapassem o espaço da sala de recursos multifuncional na escola. Tal discussão se faz possível especialmente em função da abordagem teórica sociointeracionista, à qual nos filiamos, e que indica que o sujeito com deficiência intelectual se constitui de forma significativa em função das trocas sociais que estabelece com o meio em que está inserido. Nesse sentido, entendemos que o Atendimento Educacional Especializado dos alunos com deficiência intelectual, na escola regular, deve estar pautado nos apoios necessários para que obtenham satisfatória inserção educacional e social.
\end{abstract}

Palavras-chave: Educação Especial; Deficiência Intelectual; Inclusão Escolar; Conceituação; Apoios.

\author{
Eliana da Costa Pereira de \\ Menezes \\ Universidade Federal de Santa \\ Maria - UFSM - RS/Brasil \\ eliana_cpm@yahoo.com.br
}

Sabrina Fernandes de Castro

Universidade Federal de Santa

Maria - UFSM - RS/Brasil

sabrinafcastro@gmail.com

\footnotetext{
Para citar este artigo:

MENEZES, Eliana da Costa Pereira de; CASTRO, Sabrina Fernandes de. Ações da Educação Especial no contexto da escola regular: problematizações sobre a inclusão de alunos com deficiência intelectual. Revista Linhas. Florianópolis, v. 17, n. 35, p. 30-44, set./dez. 2016.
} 


\title{
Actions of Special Education in the context of regular school: problematizations on inclusion of students with intellectual disabilities
}

\begin{abstract}
This proposal is the result of our experiences (in the condition as advisors) on the initiation actions to teaching developed in regular schools by academic students of Special Education at the Federal University of Santa Maria (UFSM) and has the goal to discuss the special education teacher performance in the context of regular school developed with the student with intellectual disabilities. In considering the concept of intellectual disability according to the idea that such deficiency should be analyzed from five dimensions - Intellectual skills, Adaptive behavior (conceptual skills, and social practices of daily life), Participation, interaction and social roles, Health (physical health, mental health, etiology) and Context (environment, culture) (AAMR, 2006), in interaction with official documents establishing the guidelines for special education in the inclusive school, it seems productive to examine how these dimensions can be used as tools for effective practices in specialized educational services beyond the scope of multifunctional resource classroom in the school. This discussion makes it possible, especially in light of the theoretical approach, social interactionist in which we are joined and which indicates that the individual with intellectual disabilities is significantly constituted due to the social exchange that is established with the environment in which he is inserted. In this sense we understand that the specialized educational services for students with intellectual disabilities in regular schools must be guided by the necessary support so that this student has a satisfactory educational and social inclusion.
\end{abstract}

Keywords: Special Education; Intellectual Disabilities; School Inclusion. 
Introdução

O que propomos neste artigo é problematizar/pensar a atuação do professor de Educação Especial frente ao aluno com Deficiência Intelectual (DI) na escola inclusiva, a partir dos sistemas de apoio presentes no conceito de deficiência intelectual apresentado pela Associação Americana de Deficiências Intelectual e do Desenvolvimento (AAIDD) ${ }^{1}$ em 2002. O interesse por essa reflexão nasceu das nossas experiências (na condição de orientadoras) de ações de iniciação à docência ${ }^{2}$ efetivadas em escolas regulares por parte dos acadêmicos dos cursos de Educação Especial da Universidade Federal de Santa Maria $(\mathrm{UFSM})^{3}$. Em tais experiências, os acadêmicos têm atuado colaborativamente com os professores do ensino regular. Isso significa que essa atuação se dá, prioritariamente, na sala regular e, em alguns momentos, em atendimentos individualizados a fim de favorecer a aprendizagem do aluno com DI em processo de inclusão escolar.

Nesse contexto, a presente discussão tem o objetivo de ampliar o entendimento do conceito de DI e, sobretudo, de propor uma utilização prática para tal conceito na própria escola regular em que os alunos com DI estão incluídos. Isso, pois, pensando na realidade atual e, mais especificamente, na realidade da rede de ensino em que atuamos (Santa Maria/RS), a partir da qual entendemos que há uma demanda significativa de alunos com DI matriculados em escolas da rede regular ${ }^{4}$, além de notarmos que 0 trabalho com esse aluno é centrado prioritariamente no espaço do atendimento individualizado e que os sujeitos que com eles interagem apontam compreensões relativas à DI baseadas na ideia da incapacidade e limitação.

\footnotetext{
${ }^{1}$ American Association on Intellectual and Developmental Disabilities é a atual denominação da Associação Americana de Retardo Mental - (AAMR - American Association on Mental Retardation).

${ }^{2}$ Tais ações têm ocorrido, sob nossa supervisão, tanto no âmbito dos estágios supervisionados presentes na matriz curricular dos cursos de Graduação em Educação Especial diurno e noturno, quanto no âmbito do Programa Institucional de Bolsas de Iniciação à Docência (Pibid), subprojeto Educação Especial/UFSM, a partir do qual os acadêmicos bolsistas devem realizar atividades com os alunos público-alvo da Educação Especial no espaço da sala de recursos e também no espaço da sala regular, na escola inclusiva, via ensino colaborativo.

${ }^{3}$ A UFSM atualmente forma professores de Educação Especial em três diferentes cursos de licenciatura em Educação Especial (diurno, noturno e ensino a distância). $O$ atual currículo do curso diurno vem sendo ofertado desde o primeiro semestre de 2008, com ênfase em déficit cognitivo, dificuldade de aprendizagem e surdez. O curso noturno teve início em 2009, com ênfase em deficiência visual, surdez/cegueira, transtornos globais do desenvolvimento, altas habilidades/superdotação e deficiência mental. O curso -EAD, por sua vez, tem ênfase em surdez e deficiência mental.

${ }^{4}$ Segundo dados do último censo escolar, no município de Santa Maria/RS há cerca de cinquenta mil alunos considerados público-alvo da Educação Especial matriculados na rede regular de ensino (municipal, estadual e particular), dos quais novecentos e oitenta e quatro possuem DI.
} 
Ao nos depararmos com essas questões, pareceu-nos produtiva uma discussão que apontasse para a compreensão de que o aluno com DI se mostrará capaz de novas aprendizagens na medida em que sobre ele forem empreendidos investimentos e apostas pedagógicas. Para fundamentar essa discussão, filiamo-nos à abordagem teórica sociointeracionista, mais especificamente nos estudos de Vygotsky (1987, 1998, 2001).

A eleição da referida perspectiva teórica deu-se em função da forma como compreendemos o processo de desenvolvimento humano. Um processo que, segundo entendemos, não é totalmente condicionado pelas circunstâncias do meio, tampouco imune a elas. A esse respeito, Carneiro (2008, p. 31) ao se referir-se à abordagem vygotskiana, afirma que

O ser humano, ao nascer, dispõe apenas de recursos biológicos característicos da espécie, que podem ser considerados a base para o processo de humanização. Mas é a convivência com o outro que vai possibilitar que esse processo se concretize. Por isso, podemos falar metaforicamente em um duplo nascimento da criança: um biológico e outro cultural. A partir do momento em que a criança nasce, progressivamente ingressa num mundo onde as relações são mediadas pelos valores, significações e verdades de sua cultura. Isso não quer dizer que ela será passivamente moldada pela cultura, mas que irá interagir com ela. É por meio dessas interações que irá se constituir como ser humano.

Trata-se, então, de um processo que se dá como resultado da interação entre aspectos sociais e aspectos biológicos. Nessa esteira, são as influências exercidas pelo ambiente cultural no qual o indivíduo nasce e se desenvolve o ponto central de seu processo de desenvolvimento. Assim, a origem das mudanças que ocorrem no homem, ao longo de sua vida, está, segundo os princípios de Carneiro (2008), na sociedade, na cultura e na sua história.

Consideramos, portanto, um sujeito que não apenas age sobre a cultura, mas interage com ela, constituindo-se como sujeito a partir dessas interações, ao mesmo tempo em que opera a constituição da própria cultura. Tal forma de compreensão destaca o papel central das interações entre os sujeitos, uma vez que é por meio das trocas estabelecidas com os outros que os significados culturais são internalizados. 0 processo de desenvolvimento caminha do plano social (relações interpessoais) para o plano individual interno (relações intrapessoais). 
Tendo em vista tais aspectos, é possível compreender que as possibilidades de desenvolvimento que uma pessoa com DI pode apresentar são determinadas principalmente pelas vivências a ela possibilitadas. Vygotsky $(1987,1998,2001)$ mostrounos que a presença da deficiência na constituição do indivíduo pode ser mais limitante, não devido aos efeitos causados na interação direta que os indivíduos estabelecem com o meio físico, mas principalmente pela qualidade das interações estabelecidas com outros sujeitos sociais.

A esse respeito, ressaltamos que as atuais políticas de educação inclusiva encontram, na teoria vygotskiana, argumentos significativos para sua defesa, uma vez que, a partir das práticas inclusivas, busca-se possibilitar que alunos com diferentes ritmos de desenvolvimento interajam em espaços não segregados, proporcionando-lhes maior qualidade nas trocas que estabelecem com os demais sujeitos.

Referimo-nos aqui a documentos como a Política Nacional de Educação Especial na Perspectiva da Educação Inclusiva (BRASIL, 2008); a Resolução nº 04, de 2009; o Decreto $n^{\circ}$ 6.711, de 2011; a Lei Brasileira de Inclusão (Lei $n^{\circ}$ 13.146, de 2015), entre outros, que militam "em defesa do direito de todos os estudantes de estarem juntos, aprendendo e participando, sem nenhum tipo de discriminação" (BRASIL, 2008, p. 01). Trata-se, assim, de pensar em uma escola "em que todos os alunos estão inseridos sem quaisquer condições pelas quais possam ser limitados em seu direito de participar ativamente do processo escolar, segundo suas capacidades, e sem que nenhuma delas possa ser motivo para uma diferenciação que os excluirá das suas turmas" (BRASIL, 2010, p. 8). Reiterando tal afirmação, a Lei Brasileira da Inclusão indica que deve ser "assegurado sistema educacional inclusivo em todos os níveis e aprendizado ao longo de toda a vida, de forma a alcançar o máximo desenvolvimento possível de seus talentos e habilidades físicas, sensoriais, intelectuais e sociais, segundo suas características, interesses e necessidades de aprendizagem" (BRASIL, 2015, p. 32).

Nessa escola que se propõe inclusiva, a atuação da Educação Especial passou a ser organizada em função das orientações presentes no Decreto $n^{\circ} 6.711$, de 17 de novembro de 2011, o qual indica, em seu artigo $2^{\circ}$, o seguinte: 
$2^{0} \mathrm{O}$ atendimento educacional especializado deve integrar a proposta pedagógica da escola, envolver a participação da família para garantir pleno acesso e participação dos estudantes, atender às necessidades específicas das pessoas público-alvo da Educação Especial, e ser realizado em articulação com as demais políticas públicas.

Art. $3^{\circ}$ São objetivos do atendimento educacional especializado:

I - prover condições de acesso, participação e aprendizagem no ensino regular e garantir serviços de apoio especializados de acordo com as necessidades individuais dos estudantes; II - garantir a transversalidade das ações da Educação Especial no ensino regular; III-fomentar o desenvolvimento de recursos didáticos e pedagógicos que eliminem as barreiras no processo de ensino e aprendizagem; e IV-assegurar condições para a continuidade de estudos nos demais níveis, etapas e modalidades de ensino.

Em consonância com o referido decreto, a Resolução $n^{\circ}$ 04, de 2 de outubro de 2009, "institui diretrizes operacionais para o Atendimento Educacional Especializado na Educação Básica, modalidade Educação Especial” e indica as atribuições do professor de Educação Especial:

Art. 13. São atribuições do professor do Atendimento Educacional Especializado: I - identificar, elaborar, produzir e organizar serviços, recursos pedagógicos, de acessibilidade e estratégias considerando as necessidades específicas dos alunos público-alvo da Educação Especial; II - elaborar e executar plano de Atendimento Educacional Especializado, avaliando a funcionalidade e a aplicabilidade dos recursos pedagógicos e de acessibilidade; III - organizar o tipo e o número de atendimentos aos alunos na sala de recursos multifuncionais; IV - acompanhar a funcionalidade e a aplicabilidade dos recursos pedagógicos e de acessibilidade na sala de aula comum do ensino regular, bem como em outros ambientes da escola; $\mathrm{V}$ - estabelecer parcerias com as áreas intersetoriais na elaboração de estratégias e na disponibilização de recursos de acessibilidade; VI - orientar professores e famílias sobre os recursos pedagógicos e de acessibilidade utilizados pelo aluno; VII ensinar e usar a tecnologia assistiva de forma a ampliar habilidades funcionais dos alunos, promovendo autonomia e participação; VIII estabelecer articulação com os professores da sala de aula comum, visando à disponibilização dos serviços, dos recursos pedagógicos e de acessibilidade e das estratégias que promovem a participação dos alunos nas atividades escolares. (BRASIL, 2009)

Nesse contexto, parece-nos possível compreender que a indicação de tais objetivos para o Atendimento Educacional Especializado (AEE) e a atribuição de tais 
funções para o professor de Educação Especial indicam a necessidade de interlocução entre Educação Especial e ensino regular, com vistas ao acompanhamento das interações que são estabelecidas entre os próprios alunos e entre professor e aluno no espaço da escola, e não exclusivamente no espaço da sala de recursos. Ao partir de tal sistemática de organização, poderiam ser efetivadas práticas focadas em um contexto social que precisa ser acompanhado, analisado e, se necessário, modificado, o que, por sua vez, evitaria a efetivação de práticas clínicas, centradas no aluno que precisa ser avaliado, reabilitado e normalizado.

Partindo desses pressupostos, ao olharmos para a inclusão escolar de alunos com DI, entendemos que é preciso a reavaliação de nossa estrutura educacional e social e a revisão de concepções e práticas em relação às pessoas com deficiências. Quando o olhar destinado a esses alunos buscar, em primeiro lugar, conhecê-los como sujeitos de aprendizagem, as práticas desenvolvidas poderão incentivar o alcance consciente e voluntário de seus comportamentos nos grupos sociais em que se desenvolvem. Tomando como embasamento tal forma de significação do sujeito (e de seu processo de desenvolvimento e aprendizagem), o olhar direcionado para a DI passa a refutar concepções clínicas sobre esta, a partir da qual tal condição, por si só, determina as possibilidades do sujeito de constituir-se como indivíduo de uma cultura.

Segundo Vygotsky, o desenvolvimento das crianças que possuem DI ocorre da mesma forma que o desenvolvimento de crianças que não possuem essa especificidade. Em suas palavras, ele afirma que "A criança cujo desenvolvimento está complicado pelo defeito não é simplesmente uma criança menos desenvolvida que seus coetâneos normais, mas desenvolvida de outro modo" (VYGOTSKY, 1997, p. 12).

Dessa forma, pensando em formas de atuação pedagógica frente ao aluno com DI, ao contrário do que historicamente lhe foi proposto, especialmente pela área da Educação Especial, devemos primar pela ação nas funções psicológicas superiores 5 . Fixados na ideia de incapacidade desses sujeitos em alcançar um pensamento formal, vimo-nos, por muito tempo, cometendo o erro de limitar a atuação desses alunos apenas

\footnotetext{
5 Funções que, segundo o autor, caracterizam o funcionamento psicológico humano: "ações conscientemente controladas, atenção voluntária, memorização ativa, pensamento abstrato, comportamento intencional" (OLIVIEIRA, 2005, p. 23), que se diferem de formas mais elementares de atuação na cultura, como atos reflexos, reações automáticas e associações simples (OLIVEIRA, 2005).
} 
ao aspecto concreto e observável dos objetos, eliminando do ensino tudo o que se relacionava ao pensamento abstrato.

[...] Ao operar exclusivamente com representações concretas e visuais, freamos e dificultamos o desenvolvimento do pensamento abstrato, cujas funções na conduta da criança não podem ser substituídas por nenhum procedimento "visual-direto". Precisamente porque a criança retardada alcança com dificuldade o pensamento abstrato, a escola deve desenvolver essa capacidade por todos os meios possíveis. 0 objetivo da escola, afinal, não consiste em adaptar-se ao defeito, senão superá-lo. (VYGOTSKY, 1997, p. 150, grifos nossos)

Essa necessidade de realização de práticas escolares que busquem a superação do "defeito" se mostra ainda mais contundente quando nos reportamos às práticas de orientação de iniciação à docência a que nos referimos anteriormente, a partir das quais se pode verificar que os alunos com DI incluídos nas escolas regulares acabam recebendo pouco investimento em função de sua suposta condição de incapacidade. Esses alunos são, na maioria das vezes, "terceirizados" para os profissionais e/ou para os acadêmicos da Educação Especial, sendo o investimento (em termos de aprendizagem) que recebem dos professores do ensino regular quase nulo.

Aqui fazemos uma ressalva. A eleição da abordagem vygotskiana - segundo a qual as possibilidades de o sujeito com DI se constituir, de forma autônoma, como partícipe de uma cultura, resultam de forma determinante da qualidade das interações sociais que ele estabelecer ao longo de sua história de vida - não nos coloca na condição de alguém que nega a existência da deficiência, mas na de quem considera que cada sujeito é único em condições, potencialidade e dificuldades. Tais aspectos, condicionados pelo meio social, podem ser tomados como ponto de partida para a identificação dos apoios a serem oferecidos com vistas a um processo de desenvolvimento e aprendizagem significativo.

O que desejamos aqui pontuar é que acreditamos ser fundamental, nas ações de inclusão escolar, que os profissionais da Educação envolvidos no processo de ensino e aprendizagem desses alunos compreendam, por exemplo, que eles podem apresentar um ritmo diferenciado se comparados a seus pares, o que poderá ser superado se houver a identificação do tipo de apoio adequado para essa especificidade. Assim, a proposta é atender ao estudante com DI partindo das suas possibilidades, enfatizando suas 
capacidades e, sobretudo, conhecendo-o e entendendo seu processo de desenvolvimento.

Nessa perspectiva, pensar a atuação dos professores envolvidos no contexto da escola regular frente ao aluno com DI com base na conceituação de DI parece-nos um bom começo. A questão conceitual de DI tem sido alvo de muita atenção por parte de educadores, médicos, psicólogos, pesquisadores e estudiosos engajados na área, porém, ainda são muitas as dificuldades encontradas. O próprio percurso histórico dessa conceituação, amplamente discutido por pesquisadores como Pessotti (2012) e Mendes (1996), evidencia esse fato.

Para nossa proposta, partimos do conceito atualmente adotado pelos órgãos oficiais brasileiros e por estudiosos da área, que foi apresentado na $10^{\mathrm{a}}$ edição do manual da AAMR, em 2002, passando a entender que $\mathrm{DI}^{6}$ é:

[...] uma incapacidade caracterizada por importantes limitações, tanto no funcionamento intelectual quanto no comportamento adaptativo, está expresso nas habilidades adaptativas conceituais, sociais e práticas. Essa incapacidade tem início antes dos 18 anos de idade. (AMERICAN ASSOCIATION ON MENTAL RETARDATION, 2006, p. 20)

Com esse conceito "o déficit na função intelectual deixa de constituir a principal característica e passa a ser um requisito para o diagnóstico desse variado grupo de síndromes. A perspectiva possibilita um enfoque muito mais otimista e fecundo no que diz respeito à evolução do indivíduo" (PAN, 2003, p. 59).

Para Paulon, Freitas e Pinho (2005, p. 13), a DI:

[...] passa a ser interpretada como um estado de funcionamento. Deixa de ser entendida como uma característica absoluta, expressa somente no indivíduo, para ser tomada como uma expressão da interação entre a pessoa com limitações no funcionamento intelectual e seu contexto. Nessa definição, também há um incremento na importância dos sistemas de apoio requeridos pelas pessoas com deficiência mental, uma questão que ganha ainda mais ênfase, a partir de 2002.

\footnotetext{
${ }^{6} \mathrm{Na} 11^{\text {a }}$ edição do Manual, efetivou-se a troca do termo "mental” por "intelectual”, mantendo a definição, a classificação e os sistemas de apoio. Vale destacar que, neste texto, a despeito de adotarmos o termo "deficiência intelectual", não temos a pretensão de discutir a substituição, pois percebemos que as discussões ainda são incipientes frente à complexidade do fenômeno dessa deficiência.
} 
Assim, ela é entendida como uma expressão de limitações no funcionamento individual do sujeito, mas dentro do contexto social em que este está inserido, considerando os fatores ambientais, sociais e a sua necessidade de apoio. hipóteses:

Para melhor entendimento da aplicação de tal conceito, a AAIDD apresenta cinco

Hipótese 1: As limitações no funcionamento atual devem ser consideradas dentro do contexto dos ambientes da comunidade característicos das pessoas da faixa etária e da mesma cultura do indivíduo. (AMERICAN ASSOCIATION ON MENTAL RETARDATION, 2006, p. 20)

Considerando tal hipótese, o sujeito deve ser avaliado nos ambientes de sua convivência, na sua casa, na escola, na comunidade, e não em ambientes isolados para tal ação.

Hipótese 2: A avaliação válida considera a diversidade cultural e linguística, e também as diferenças na comunicação, nos fatores sensoriais, motores e comportamentais. ( AMERICAN ASSOCIATION ON MENTAL RETARDATION, 2006, p. 20)

A hipótese 2 lembra-nos de considerar as características culturais do contexto social do indivíduo, incluindo etnia, comunicação não verbal, costumes, etc.

Hipótese 3: Em cada indivíduo, as limitações frequentemente coexistem com as potencialidades. ( AMERICAN ASSOCIATION ON MENTAL RETARDATION, 2006, p. 20)

Essa hipótese, que nos é particularmente cara, foca nas potencialidades do indivíduo. Levando em consideração a complexidade de todo ser humano, as pessoas com DI, provavelmente, possuem habilidades mais desenvolvidas em algumas áreas do comportamento adaptativo, potencialidades que devem ser exploradas e enfatizadas no cotidiano escolar.

Hipótese 4: Um propósito importante ao descrever as limitações é o de desenvolver um perfil aos apoios necessários. (AMERICAN ASSOCIATION ON MENTAL RETARDATION , 2006, p. 20) 
O diagnóstico de deficiência não deve ser um fim. O principal objetivo de descrever as limitações do sujeito deve ser a possibilidade de se criar planos de desenvolvimento baseados nos apoios necessários. Aqui está calcada nossa crença de que o diagnóstico pode trazer possibilidades de se pensar atividades educacionais específicas, de acordo com o perfil de apoio que o sujeito necessita, a serem desenvolvidas na própria escola em que o sujeito está inserido.

Hipótese 5: Com os apoios personalizados apropriados durante um determinado período de tempo, o funcionamento da vida da pessoa com retardo mental em geral melhora. (AMERICAN ASSOCIATION ON MENTAL RETARDATION , 2006, p. 20)

A última hipótese apresenta-nos a certeza de que, se pensarmos o desenvolvimento de planos específicos voltados para a necessidade de apoio que o sujeito possui, as respostas esperadas serão alcançadas: com os apoios adequados, os indivíduos com DI apresentarão resultados significativos. Segundo a AAIDD, com a aplicação de tal hipótese, o antigo equívoco de que as pessoas com DI permanecem estagnadas por toda a vida irá se desfazer, ou seja, se adequadamente trabalhados os apoios necessários, o funcionamento das pessoas com este tipo de deficiência tende a melhorar.

Ao considerarmos essa conceituação de DI, baseada no modelo teórico multidimensional, apresentado pela AAIDD, outro ponto parece-nos fundamental a ser considerado: as cinco dimensões que abrangem o indivíduo e o seu contexto. A descrição de cada uma dessas dimensões deve servir como base para um planejamento pedagógico adequado, também, na escola.

A saber, as cinco dimensões são: habilidades intelectuais; comportamento adaptativo (habilidades conceituais, sociais e práticas de vida diária); participação, interações e papéis sociais; saúde (saúde física, saúde mental, etiologia) e contexto (ambientes, cultura) (AMERICAN ASSOCIATION ON MENTAL RETARDATION , 2006). Essas dimensões focam nos elementos essenciais que devem compor tal conceito: a pessoa, os ambientes e os apoios. 
Na prática, essas dimensões podem ser, resumidamente, descritas da seguinte forma:

- Habilidades intelectuais: “capacidade mental geral que inclui raciocínio, planejamento, resolução de problemas, pensamento abstrato, compreende ideias complexas, aprender rapidamente e aprender com a experiência" (AMERICAN ASSOCIATION ON MENTAL RETARDATION , 2006, p. 214);

- Comportamento adaptativo: conjunto de habilidades necessárias para o cotidiano do indivíduo, como, por exemplo: Habilidades Conceituais (leitura e escrita); Habilidades Sociais (cumprimento de regras sociais) e Habilidades Práticas (atividades de vida diária, como preparar seu próprio alimento);

- Participação, interações e papéis sociais: refere-se ao modo que o sujeito participa e interage nos espaços em que convive. Os papéis sociais são determinados pelo contexto do grupo social em que estamos inseridos;

- Saúde: "definida como um estado de completo bem-estar físico, mental e social”, a condição de saúde implica diretamente no funcionamento das outras dimensões (AMERICAN ASSOCIATION ON MENTAL RETARDATION , 2006, p. 216). Nessa dimensão, considera-se a etiologia, ou seja, a causa e a origem da DI;

- Contexto: enfatiza o meio no qual o indivíduo está inserido, considerando a família, a comunidade, a escola e, em um contexto mais abrangente, as questões culturais e sociopolíticas da sociedade.

Assim, tanto as hipóteses quanto as dimensões apresentadas pela AAIDD ( AMERICAN ASSOCIATION ON MENTAL RETARDATION, 2006) nos fazem pensar em uma série de fatores importantes para a atuação pedagógica frente ao aluno com DI. Primeiramente, pensamos a respeito de questões referentes aos fatores culturais, ambientais, sociais, linguísticos que devem ser considerados para a avaliação e o diagnóstico deste tipo de deficiência. Outro aspecto é o destaque para as potencialidades, lembrando que cada ser humano é único e que as pessoas com DI poderão ter habilidades, potencialidades e capacidades a desenvolver desde que haja investimento nelas. Por último, evidenciamos a importância dos apoios que a pessoa precisa para sua aprendizagem, seu desenvolvimento e uma melhor qualidade de vida, 
destacando o papel fundamental da atuação dos professores envolvidos no contexto da educação desses sujeitos.

\section{Aspectos importantes para continuidade da discussão...}

Ao propormos a presente discussão, partimos de inquietações sentidas durante as ações de supervisão docente sobre a prática de estagiários de Educação Especial no contexto da escola regular frente a alunos com DI. Nesse momento, nossa principal discordância com o que estava posto dizia respeito ao olhar clínico que embasava tanto a atuação dos estagiários, quanto a atuação dos demais professores das escolas em relação a esses alunos. Tal forma de compreender o sujeito resulta em uma intervenção pedagógica centrada prioritariamente no aluno e operacionalizada prioritariamente no espaço da sala de recursos. Parece haver, nessa perspectiva, uma compreensão de que, para que o aluno com DI alcance condições de aprendizagem na escola, faz-se necessário que, sobre ele (e somente sobre ele), sejam feitos investimentos pedagógicos. Por essa lógica, é no aluno que são localizados todos os motivos de suas dificuldades de desenvolvimento e limitações nas aprendizagens.

Ocorre que nos colocamos na contramão dessa lógica, pois compreendemos que as ações e os investimentos feitos sobre o aluno com DI de forma isolada resultarão em efeitos pouco significativos, uma vez que não se encontram exclusivamente nele as justificativas para sua forma de responder ao que lhe é proposto na escola, mas principalmente no contexto e nas interações que ele estabelece. Tal forma de significar o aluno com DI resulta, como já indicamos, do embasamento vygotskiano eleito para fundamentar nossa atuação docente e a partir do qual compreendemos que o sujeito é fruto das relações sociais a que é submetido em determinado contexto histórico e cultural. Nessa perspectiva, a ação do professor de Educação Especial não pode limitar-se à atuação na sala de recursos, devendo, sim, ter como alvo principal os espaços em que interações com os demais alunos são possíveis.

Ao estabelecer tal forma de compreensão sobre como deve se dar a atuação do professor de Educação Especial na escola regular, acreditamos estar corroborando para a efetivação de práticas inclusivas, uma vez que, nessa perspectiva educacional, a escola 
precisa constituir-se como um espaço que atenda a todos, cabendo à Educação Especial não mais substituir as práticas do ensino regular, mas sim complementá-las e/ou suplementá-las. Nesse sentido, ao procurarmos enfrentar as inquietações sentidas durante nossa experiência com a iniciação à docência, um exercício importante proposto aos futuros professores de Educação Especial foi o de pensar seu aluno com DI inserido na sala de aula regular a partir de cada uma das dimensões propostas pela atual conceituação da AAIDD, desafiando-os a traçar metas e objetivos a serem alcançados com vistas à aprendizagem por parte do aluno.

Desse modo, para finalizar, ressaltamos a necessidade de continuarmos a discutir a DI e a atuação docente da Educação Especial na escola regular, com base na interlocução entre a proposição conceitual apresentada pela AAIDD, as diretrizes para a Educação Especial presentes nos documentos legais e os embasamentos teóricos da perspectiva vygotskiana. Parece-nos que os efeitos da interlocução entre essas três instâncias podem ser significativamente produtivos para os processos de escolarização dos alunos em questão, para o percurso formativo dos professores de Educação Especial e especialmente potentes para a superação de práticas em Educação Especial desenvolvidas ainda hoje sob um viés clínico e limitante, que, sem dúvida, precisa ser superado.

\section{Referências}

AMERICAN ASSOCIATION ON MENTAL RETARDATION. Retardo mental: Definição, Classificação e Sistemas de Apoio. Porto Alegre: Artmed, 2006.

BRASIL. Ministério da Educação. Lei n. 13.146 de 2015: Lei Brasileira de Inclusão -. Brasília: DF, 2015. Disponível em: http://www.planalto.gov.br/ccivil_03/_Ato2015-2018/2015/Lei/L13146.htm. Acesso em 08 de maio de 2015.

BRASIL. Ministério da Educação. Decreto n 7.611 de 2011. Brasília, DF, 2011. Disponível em: http://www.planalto.gov.br/ccivil_03/_ato2011-2014/2011/decreto/d7611.htm. Acesso em Acesso em 08 de maio de 2015.

BRASIL. Ministério da Educação. Atendimento educacional especializado - A escola comum inclusiva. Brasília, DF, 2010.

BRASIL. Ministério da Educação. Resolução nº 4 de 2009. Brasília, DF, 2009. Disponível em: http://portal.mec.gov.br/dmdocuments/rceb004_09.pdf. Acesso em 08 de maio de 2015. 
BRASIL. Ministério da Educação. Política Nacional da Educação Especial na perspectiva da Educação Inclusiva. Brasília, DF, 2008. Disponível em:

http://peei.mec.gov.br/arquivos/politica_nacional_educacao_especial.pdf. Acesso em 08 de maio de 2015.

CARNEIRO, Maria Sylvia. Adultos com síndrome de down: a deficiência mental como produção social. Campinas: Papirus, 2008.

MENDES, Enicéia Gonçalves. Evolução histórica da concepção científica de deficiência mental. In: GOYOS, Celso, ALMEIDA, Maria Amélia e SOUZA, Deisy de. Temas em educação especial. São Carlos: EDUFSCar, 1996. p. 119 - 136.

OLIVEIRA, Marta Kohl. Vygotsky: aprendizado e desenvolvimento, um processo sóciohistórico. São Paulo: Scipione, 2005.

PAN, José Ramón Amor. Afetividade e sexualidade na pessoa portadora de deficiência mental. São Paulo: Edições Loyola, 2003.

PAULON, Simone Mainieri; FREITAS, Lia Beatriz de Lucca; PINHO, Gerson Smiech. Documento subsidiário à política de inclusão. Brasília: Ministério da Educação, Secretaria de Educação Especial, 2005.

PESSOTTI, Isaías. Deficiência mental: da superstição à ciência. Editora: ABPEE, 2012.

VYGOTSKY, Lev Seminovitch. Obras escogidas: fundamentos de defectología. Madrid: Vísor, 1997. t. 5 .

VYGOTSKY, Lev Seminovitch. Linguagem, desenvolvimento e aprendizagem. São Paulo: Ícone/EDUSP, 2001.

VYGOTSKY, Lev Seminovitch. A Formação social da mente. São Paulo: Martins Fontes, 1998. $6^{\mathrm{a}}$ ed.

VYGOTSKY, Lev Seminovitch. Pensamento e linguagem. São Paulo: Martins Fontes, 1987.

Recebido em: 03/03/2016

Aprovado em: 20/05/2016

Universidade do Estado de Santa Catarina - UDESC Programa de Pós-Graduação em Educação - PPGE

Revista Linhas

Volume 17 - Número 35 - Ano 2016 revistalinhas@gmail.com 